\title{
High School Students' Views of Mathematics as a Tool for Social Critique
}

\author{
By Anastasia Brelias*
}

Critical education scholars contend that schools ought to play a role in the transformation of inequitable institutions and social arrangements. In part, this entails educating students in the academic disciplines, viewed as powerful lenses through which students might see the world in order to better understand why things are the way they are and how they might be different. Using a critical theoretical perspective on mathematics literacy, this study examined high school students' views of mathematics in light of their experiences with mathematical investigations of social problems. Qualitative research methods were used in data collection and analysis. Data were gathered in a statistics class and a mathematical modeling class during fifty days of classroom observations, interviews with sixty students and two teachers, and a review of student work. Spradley's analytic techniques, known as domain analysis, were used to identify themes in the data. Students in this study indicated that their classroom experiences caused them to rethink their ideas about mathematics. They described mathematics as an indispensable tool for disclosing social injustices. Some students stated that prior to their investigations they took equality in the US for granted. Even students who suspected biases in social practices had not figured on the subtle form they sometimes take. At the same time, they indicated that applying mathematics to social problems is not unambiguous, unproblematic, and as objective as they had previously thought. As a result, applications should be scrutinized with respect to their assumptions, methods, and conclusions. Critical mathematics education scholars argue that students will construct views of mathematics and society that are less mystified if they experience the use of mathematics as a tool for social critique in the classroom. This study supports their argument.

\section{Introduction}

What shall we teach secondary school students about mathematics? This question is the subject of considerable debate in conversations about curricular reform in the United States of America. Critical mathematics education scholars proffer this answer: Teach students how to use mathematics as a tool

${ }^{*}$ Assistant Professor, Northeastern Illinois University, USA. 
for social critique. The gravity of the problems that confront humanity requires that citizens of the world bring all types of disciplinary knowledge, including mathematics, to bear on their resolution. Of particular interest to these scholars is the problem of social inequality that persists in the USA and elsewhere. Viewing the world through a lens informed by critical theory, they argue that the inequitable distribution of social goods and power is the result of the control that certain social groups have historically exercised over major societal institutions. Schools and other institutions have helped perpetuate an unjust social order, in part, by promoting dominant ideologies about how the world is and works. Critical scholars advocate teaching school subjects like mathematics as compelling tools for contesting these ideologies (Ernest, 1991; Frankenstein, 1990; Skovsmose, 1994b).

At the same time, we must teach students to critique societal uses of these tools. Increasingly used to "describe," "predict" and "prescribe," mathematics in its myriad applications, "regulate[s] our lives" (Davis \& Hersch, 1988, 120121) in ways that may or may not be beneficial. Furthermore, technological progress, which is aided by advances in mathematics, does not ensure social progress. As Ubiratan D'Ambrosio (2008) states, "We do not want our student [s] to become bright scientists creating new weaponry and instruments of oppression and inequity" (p. 39).

The mathematics curriculum in secondary schools is a key influence on students' thinking about mathematics, and arguably, their thinking about the world through their mathematical investigations of it (National Council of Teachers of Mathematics [NCTM], 2000). Regrettably, after years of schooling, it appears as though far too many students in the USA "see the social utility of mathematics not in terms of citizenship and life skills, but instead merely as a ticket to a good job and success" (Wilkins, 2000, p. 414). Furthermore, youth surveyed in the International Citizenship Education Policy Study Project felt that what they were studying in school had little bearing on their lives outside of school and that the connections between school subjects and their lives were seldom explicitly made in the classroom (Cogan, J., 2000). These findings suggest that schools are failing to provide many students with sufficient opportunities to develop the kind of mathematics literacy that is suitable for understanding social problems and the disposition to use mathematics to solve them.

In recent years, recommendations for the reform of the high school mathematics curriculum have emphasized the importance of providing high school students with ample opportunities to investigate societal problems (Common Core State Standards for School Mathematics, 2010; NCTM, 2000). This paper is based on a study that examined the views of mathematics held by high school students in the USA in light of their classroom experiences using mathematics to investigate societal problems. Furthermore, it examines their views using a critical theoretical perspective on mathematics literacy.

\section{Literature Review and Conceptual Framework}


While a general consensus exists regarding its importance in contemporary society, what mathematics literacy should encompass is not self-evident. Underlying the different conceptions of mathematics literacy that compete for power in schools and public discourses about education are different perceptions of social reality, the purpose of schools, the nature of mathematics, and aims for mathematics education (Ernest, 1991). A conception of mathematics literacy that has been termed "critical mathematics literacy" (Frankenstein, 1990), or alternately, mathemacy (Skovsmose, 1994b) informed the design of this study.

\section{Critical Mathematics Literacy}

Over time the word "critical" has acquired various meanings in relation to mathematics literacy. A connotation that is rooted in the instrumental rationality of the Enlightenment informs traditional conceptions of mathematics literacy (Bohl, 1998; Skovsmose, 1994b). In these conceptions, critical thinking in mathematics involves "the analysis of a situation's technical or abstracted logical components" (Bohl, 1998, p.16) using the concepts, procedures and standards of mathematics together with the general competencies associated with rational and logical thought.

Critical mathematics literacy incorporates critical thinking in mathematics, but also embodies the connotation of "critical" that is rooted in the critical social theory of the Frankfurt School (Bohl, 1998; Skovsmose, 1994b). As the promise of the Enlightenment for liberating humanity from suffering and oppression went unrealized, the theorists of this school developed critiques of extant social systems and the societal myths that underpinned them. The word critical came to connote "the marriage of a critique of social ideologies with a set of social-justice oriented commitments" (Bohl, 1998, p.3). Thus, in the conception of mathematics literacy known as critical mathematics literacy, mathematics is a tool for "ideology-critique" (Burbules, 1995, p. 53). Scholars argue that mathematics can provide evidence in support of arguments that many problems are due to inequitable social arrangements rather than individual failure (Frankenstein, 1990; Gutstein, 2003, 2006). Frankenstein (1989) has described critical mathematics literacy as "understand[ing] mathematics in a way that will enable you to use that knowledge to cut through the 'taken-for-granted' assumptions about how our society is structured" (p. 2).

Furthermore, critical mathematics literacy entails more than knowing mathematics. It is "knowledge of mathematical content embedded in a contextual framework" (Wilkins, 2000, p. 406) that incorporates social, economic, and political realities. It is understanding the role of mathematics in society - together with the values, assumptions, ideologies and interests - that influence the development and application of mathematics (Apple, 1992, 1995; Frankenstein, 1990, 1995; Gellert, Jablonka, \& Keitel, 2001; Noddings, 1993; 
Skovsmose, 1994a, 1994b; Tate, 1995. "For whom and for whose benefit is mathematics created and used?" is a question at the heart of critical mathematics literacy (Gellert, Jablonka \& Keitel, 2001).

The creation of a more just and humane world will require the active engagement of citizens in collective deliberations about civic issues. Skovsmose (1994a) views critical mathematics literacy as the competence needed to take a justified position in deliberations in which mathematics plays a part. Mathematics may illuminate issues; however, it may also obscure them (Porter, 1995). Thus, citizens who demonstrate critical mathematics literacy know what lies below the surface of many social, economic, and political issues that are framed mathematically. They also know what mathematics can (and cannot) contribute to a better understanding of these issues.

\section{Reflection and Critical Mathematics Literacy}

Skovsmose argues that reflective competence is a key element of critical mathematics literacy. He defines it as "competence in evaluating applications of mathematics" (1994a, p. 35). For Skovsmose (1994b) reflecting on an application of mathematics to a real world problem entails examining (a) the assumptions underlying the application, (b) the processes involved in the application's development, and (c) the effects of using mathematics to address the problem. Other critical education mathematics scholars have argued the importance of interrogating these aspects of mathematics applications to being critically literate about the uses of mathematics in society (Bohl, 1998; Christiansen, 1996; Frankenstein, 1995).

Applications of mathematics embody assumptions emanating from system descriptions, theories (and perhaps biases), and methodologies. Reflection on mathematics applications requires scrutinizing their assumptions-making them explicit and determining whether they are sensible while examining choices involved in their adoption, the basis of these choices, and whose interests or agendas they serve (Bohl, 1998; Skovsmose, 1994b; Tate, 1996).

Reflecting on a mathematics application requires careful oversight of the different processes involved in its design and implementation. Skovsmose (1994b) contends that there are inherent "problems and uncertainties connected with the transitions" (p. 111) among processes involved in the development of a mathematical model due in part to the different languages they employ. $\mathrm{He}$ distinguishes among four basic languages: natural, systemic, mathematical, and algorithmic. A problem in need of understanding or resolution is initially articulated in natural language. Systemic language highlights relevant aspects of the problem and depicts them using technical terms based on a particular theoretical framework. These aspects of reality become part of a system, the conceptualization of reality for the model. Mathematical language is used to describe relationships among parameters that are theorized in systemic language, thus formalizing these relationships. Finally, algorithmic language provides a series of steps for determining numerical values. 
Reflecting on mathematics applications also requires evaluating the effects of using mathematics to address the problem. This may include questioning the relevance of a mathematical approach to the problem-solving process. One might also reflect on whether the mathematical approach used was reliable or whether a better mathematical approach could have been used (Gellert, Jablonka, \& Keitel, 2001; Skovsmose, 1994b). Skovsmose (1994b) argues that one of the effects of using mathematics in a problem situation is that it constrains "problem identification," "the structure of argumentation," "the basis for critique," and "the scope of possible actions" (pp. 111-113).

In conceptualizing reflection on mathematics as a problem-solving tool, Christiansen distinguishes between two types of reflections, those guided by "technological purpose[s]" and those guided by "a critical interest in recognizing what is restrictive and oppressive" (Christiansen, 1996, p. 125). The goal of the former type of reflection is to obtain the highest quality model for a problem situation. As a result, these technically oriented reflections are concerned with such matters as whether the application's calculations address the right problem (often narrowly defined) and have been performed correctly, the reasonableness of assumptions and methods in view of what was to be mathematized, and the reliability of results obtained. In contrast, the latter type of reflection unites social, political, and ethical concerns with technical considerations in appraising a mathematics application and addresses the broader consequences of using mathematics to address a problem- how mathematics affects the perception of the problem, what the actual purpose of using mathematics in this situation is, and what functions mathematics performs. It is important to note that these critically oriented reflections are frequently dismissed or supplanted by technical concerns when mathematical applications are discussed both in schools and outside of schools (Bohl, 1998; Christiansen, 1996; Skovsmose, 1994b; Tate, 1996).

\section{Dominant Beliefs about Mathematics}

Critical mathematics education scholars argue that mathematics applications are insufficiently scrutinized in large part because of mathematics' reputation as an infallible tool (Ernest, 1991; Skovsmose, 1994b). As a consequence of their schooling, most people view mathematics as the paradigmatic discipline of certain knowledge. Scholars have challenged this absolutist view of mathematics knowledge (Ernest, 1991 Skovsmose, 1994b). They assert that mathematics does not attain the ideals of certainty, absolute truth, objectivity, and neutrality typically ascribed to it and presumably assured by mathematical proof. When these attributes are uncritically ascribed to applications of mathematics, mathematics becomes mystified. Borba and Skovsmose (1997) refer to mathematics' functioning as "ideology of certainty" (p. 17) in Western societies: mathematics can be used to make sense of virtually any situation, and its use in a situation vouches for the certainty of 
results obtained. Yet, certainty is not always attainable when mathematics is applied to real-world problems. Statistics are qualified by margins of error and confidence levels. Furthermore, mathematics does not always provide solutions to problems of social import. For instance, free and fair elections are a crucial component of the political machinery in a democracy. Yet, mathematics cannot determine the optimal voting method (Borba \& Skovsmose, 1997).

Critical mathematics education scholars contest other beliefs associated with a mystified image of mathematics. They argue that mathematics in its applications is non-neutral, value-laden, and not objective, insofar as objectivity is traditionally conceived. This is because it does not exist apart from how and why it is used, and in whose interest it is used - thus necessarily reflecting values, relations of power and competing interests (Frankenstein, 1995; Gellert, Jablonka, \& Keitel, 2001; Skovsmose, 1994b; Tate, 1996). The creation of a mathematical model typically forces one to transform an imprecise and complex situation into a simpler and more clearly defined mathematical structure. As a result of this simplification and because mathematics objects have understood properties and behaviors, a mathematical model has the potential to provide insights that are not discernible during a nonmathematical investigation of the situation. However, a model embodies many choices, both mathematical and non-mathematical in nature-choices about what to model, which elements of the situation (and their relationships) to include, and what mathematical tools can best express them. Because factors external to the discipline (as well as internal to it) influence how mathematics is applied, mathematics is not the objective, non-neutral, value-free tool it is commonly perceived to be.

From a critical perspective, a concerning consequence of dominant beliefs about mathematics is that they mystify mathematics, thereby, inhibiting the questioning of received knowledge about mathematics, its applications, and the functions it performs in technologically advanced societies (Apple, 1992; Davis, 1993; Gellert, Jablonka, \& Keitel, 2001; Skovsmose, 1994b). Therefore, a mathematics literacy that is truly critical requires a demystified view of mathematics.

\section{Research on Students' Views of Mathematics as a Tool for Social Critique}

Critical mathematics education scholars argue that mathematics applications in the curriculum that address socially relevant problems and highlight social injustices (local, national and/or global in scope) are indispensable instruments of social criticism and that they can positively impact students' critical social awareness (Brantlinger, 2007; Christiansen, 1996; Frankenstein, 1995; Gutstein, 2003, 2006; Skovsmose, 1994b; Tate, 1995; Turner, 2003). Empirical studies of applications involving concrete instances of discrimination and exploitation (or privileging), based on class, race, gender, and other social group identifiers support critical scholars' claims that they enhance students' social awareness (Frankenstein, 1995; Gutstein, 
2003, 2006; Tate, 1995; Skovsmose, 1994b; Turner, 2003). By bringing to light some of the contradictions between sociopolitical ideals and lived experiences, these mathematical investigations led to changes in students' perceptions of social life that are consonant with an emerging critical social awareness. Furthermore, a positive change occurred in most students' perceptions of the utility of mathematics for understanding social issues (Brantlinger, 2007; Christiansen, 1996; Frankenstein, 1995; Gutstein, 2003; Tate, 1995; Turner, 2003).

There is a dearth of studies of high school students' views of mathematics as a tool for social critique, however (Brantlinger, 2007). Moreover, US field studies of critical mathematics literacy have been conducted largely in segregated schools serving traditionally underachieving or underrepresented social groups in mathematics - students of color, particularly AfricanAmerican and Mexican-American students; and low-income students (Brantlinger, 2007; Gutstein, 2003; Tate, 1995; Turner, 2003). The study reported in this paper addresses this gap in the research literature. Collectively, its students are diverse with respect to race, ethnicity, social class, and mathematical achievement and interest. Although teaching for critical literacy originated as a "pedagogy for the oppressed" (Freire, 1995), it is arguably a pedagogy for all as the attainment of a more just world is likely to require the support of allies from privileged social groups.

\section{Methods and Data Sources}

Qualitative research enables a rich description of the "meaningperspectives" of participants in social practices (Erickson, 1986, p. 121). Thus, qualitative research methods were well suited for the purposes of this empirical study and were used in data collection and data analysis.

\section{Research Sites and Participants}

The research sites were two mathematics classes- mathematics modeling and statistics, in two selective enrollment public high schools in the USA. Admission to both schools is highly competitive and based on student grades and performance on nationally normed tests. Both schools are committed to a diverse student body, so race and other demographic factors are also considered in admitting students. Mathematics modeling and statistics are among the most application-driven courses in the high school mathematics curriculum and, thereby, promising courses for engaging students in mathematically-based investigations of social problems. Between them, the curricula at the two research sites included a range of applications with respect to mathematical content and social issues. The teacher participants have more 
than ten years of mathematics teaching experience and created the applications included in this study. A profile of student participants is provided in Table 1.

Table 1. Class Profiles

\begin{tabular}{|c|c|c|}
\hline $\begin{array}{c}\text { CLASS } \\
\text { CHARACTERISTICs } \\
\end{array}$ & $\begin{array}{c}\text { NORTH } \\
\text { HIGH SCHOOL }\end{array}$ & $\begin{array}{c}\text { CENTRAL } \\
\text { HIGH SCHOOL }\end{array}$ \\
\hline Class size & 30 & 39 \\
\hline \multicolumn{3}{|l|}{ Race/Ethnicity (\%) } \\
\hline White & $24 \%$ & $74 \%$ \\
\hline Asian Pacific & $7 \%$ & $21 \%$ \\
\hline Black & $33 \%$ & $5 \%$ \\
\hline Hispanic & $23 \%$ & $0 \%$ \\
\hline Bi-racial & $13 \%$ & $0 \%$ \\
\hline \multicolumn{3}{|l|}{ Gender (\%) } \\
\hline Female & $37 \%$ & $49 \%$ \\
\hline Male & $63 \%$ & $51 \%$ \\
\hline SES & $\begin{array}{l}\text { Mostly poor and } \\
\text { working class }\end{array}$ & Mostly middle and upper class \\
\hline Achievement/Interest & $\begin{array}{c}\text { Mostly } \\
\text { underachievers at } \\
\text { their school with } \\
\text { little interest in math }\end{array}$ & $\begin{array}{c}\text { Mixed achievement levels and } \\
\text { interest }\end{array}$ \\
\hline
\end{tabular}

\section{Data Collection}

Data were gathered through (1) classroom observations, (2) semistructured interviews, and (3) a review of student work. Interviews were conducted with both teachers and with all students who consented to be interviewed and were available for interviews: $93 \%$ of students (28 out of 30) in the mathematics modeling class and $82 \%$ of students (32 out of 39 ) in the statistics class. Lessons involving seventeen socially relevant mathematics applications were observed. The applications, nine at North High School and eight at Central High School, addressed a wide range of social justice issues of either the students' or teachers' choosing. These issues include (but are not limited to) income distribution, the distribution of scarce resources, school funding, toxic waste dumps, the Iraq War, community attitudes towards gay marriage, racial discrimination in capital punishment and affirmative action policies. The applications incorporated mathematics topics mainly from algebra and statistics. A sample of students was interviewed individually or in groups following each application. A sample of student work (from at least five students) was collected for each application. 


\section{Data Analysis}

An inductive approach was used in the analysis of students' views of mathematics as a tool for social critique. Spradley's analytic techniques, known as domain analysis, were used to generate "categories of meaning" (1980, p. 88) which culminated in the identification of themes in students' views. The domains or categories emerged from the study's data even as some categories were foretold by the research literature and the study's interview questions.

A domain incorporates "included terms" and a "cover term" linked by a semantic relationship (Spradley, 1980). Included terms specify members of the domain. A cover term names the domain to which the included terms belong. While cover terms were generally researcher-generated, included terms were terms that students used to describe mathematics. For example, a domain in this study was "image of mathematics" (cover term). It contained the following members (among others): "objective," "precise," "untrustworthy" (included terms). The semantic relationship for this domain was "attribution." Each of the included terms was an "attribute" or characteristic of the "image" of math that students voiced. The examples in Table 2 illustrate some semantic relationships used to generate the initial categories for data analysis.

Seven major categories (with subcategories) resulted from the consolidation of tens of categories generated by domain analysis: (1) attributes of mathematics, (2) value of mathematics, (3) uses of mathematics, (4) challenges of developing mathematics applications, (5) influences on the application of mathematics, (6) influence of applications on thinking about mathematics and social issues, and (7) evaluation of mathematics applications. These categories were further consolidated into the following three categories benefits, shortcomings, and evaluation, each of which contained multiple subcategories and were the basis of themes in students' views of mathematics.

Table 2. Semantic Relationships in Student Descriptions of Mathematics

\begin{tabular}{|c|c|c|c|}
\hline $\begin{array}{c}\text { SEMANTIC } \\
\text { RELATIONSHIP }\end{array}$ & INCLUDED TERMS & FORM & COVER TERM \\
\hline Attribution & Objectivity & is an attribute of & Image \\
\hline Attribution & Precision & is an attribute of & Image \\
\hline Attribution & Untrustworthy & is an attribute of & Image \\
\hline Strict Inclusion & $\begin{array}{c}\text { "Translating fairness into } \\
\text { math" }\end{array}$ & is a kind of & Challenge \\
\hline Strict Inclusion & $\begin{array}{c}\text { "When they're ethical } \\
\text { problems, math doesn't } \\
\text { help" }\end{array}$ & is a kind of & Limitation \\
\hline Strict Inclusion & "Proves hunches true" & is a kind of & Strength \\
\hline Means-end & $\begin{array}{c}\text { "Check any assumptions } \\
\text { made" }\end{array}$ & is a way to & $\begin{array}{c}\text { Scrutinize } \\
\text { applications }\end{array}$ \\
\hline
\end{tabular}




\section{Results and Discussion}

Three primary themes in students' descriptions of mathematics emerged from data analysis.

1. Mathematics is an essential tool for social critique.

Students indicated that mathematics (1) provides the "facts" of the matter or alternately, evidence or proof of an injustice, (2) is "objective" ("two is two to everyone" as one student put it; also, mathematics has rules which govern its use, thereby, constraining bias), (3) is authoritative in contemporary society, and (4) provides a compelling justification for individual and societal beliefs and actions for the reasons previously stated.

2. Mathematics has limitations as a tool for social critique.

Students indicated that mathematics (1) oversimplifies complex social issues, (2) objectifies human beings, thereby distancing us from their suffering and struggles, (3) does not adequately explain societal problems, (4) is irrelevant for answering moral questions, and (5) is inaccessible to the general public and largely underutilized as an instrument for social change.

3. It is important to carefully examine the methods used and the motives underlying applications of mathematics to social justice issues.

Students consistently mentioned the need to be "critical" about mathematics' use as a tool for social critique. For these students, being "critical" means scrutinizing an application's assumptions, methods, and conclusions and the intentions of the developer or user of the application.

These three themes were true for every student interviewed and consistent across both research settings. That is to say, all students identified some situations in which mathematics would be an indispensable tool for examining social issues (theme 1), or an inadequate one (theme 2). Furthermore, all students indicated that it was important to scrutinize applications of mathematics to social issues (theme 3). Although there was consistency in the content of some descriptions related to these themes, there was variation in others. That is, some ideas supporting these themes were articulated by all students or the majority of students, and other ideas were expressed by a few students, or a lone student at each research site. The following discussion examines students' views of mathematics from a critical theoretical perspective. It focuses on the ways in which they challenged hegemonic ideas about society and mathematics. 


\section{Mathematics: A Tool for "Ideology-Critique"?}

Critical mathematics education scholars argue that mathematics is an invaluable tool for "explod[ing] the myths" (Frankenstein, 1994, p. 25) about social life by revealing the contradictions between professed democratic values and the lived experiences of oppressed social groups. Students overwhelmingly concurred with critical education theorists on this point. Their reflections on classroom inquiries demonstrate that they believe that fundamental social inequalities persist in the USA and that mathematics provides "hard evidence" of them (Gian). Some students reflected that prior to some investigations they took equality in the United States for granted. Even students who suspected biases in institutions and social practices, had not anticipated the subtle form they sometimes take. All students indicated that their inquiries enabled them to see things as they are. Some reported being "troubled" by their findings.

\section{Mathematics: An "Ideology of Certainty"?}

In the dominant view of mathematics, mathematics is certain, objective, neutral, value-free, and all-powerful. Borba and Skovsmose (1997) refer to this view as an "ideology of certainty" (p. 17). Students largely contested the dominant view of mathematics in its applications to social issues. They reflected that mathematical inquiries are subject to a number of uncertainties. For example, conclusions are bound up with margins of error and confidence levels. Furthermore, students were unanimous in the view that many social issues could not be unproblematically mathematized. In many inquiries, for example, they grappled with the question of how to measure social inequality. In the "transition" from social issue to its mathematization, things have a tendency to get "muddled," as Dinesh put it. Students' recognition of this recalls Skovsmose's discussion of the importance of awareness of "the problems and uncertainties connected with transitions between the different...language[s] ... involved" in the process of developing a mathematics application (Skovsmose, 1994b, p. 111).

Students viewed inquiries which revealed statistically significant imbalances as a starting point, not an endpoint to a discussion about the fairness of social practices. The knowledge we obtain from them, though extremely useful, is necessarily incomplete. Moreover, students did not see mathematics as a relevant tool for answering some of the all-important questions that might be asked, thereby challenging the myth of mathematics as an all-powerful tool. So, for example, although mathematics can tell us how the capital punishment is working, it cannot in and of itself settle the larger question of whether we should have a death penalty, students said. These students essentially recognized that "mathematics does not allow for normative discourse" (Skovsmose, 1994b, p. 110). Thus, although students embraced the conclusions established by their mathematically-driven inquiries, these 
conclusions appeared less certain and less powerful than they once might have. Students seemed to accept these conclusions as truths, to be sure, however, as tentative rather than absolute truths.

Critical mathematics education theorists argue that mathematics applications are not objective as the term as objective is traditionally conceived. Students also contested the objectivity of mathematics applications. Because people "put part of themselves in the math" (Matthew), mathematical inquiries about social issues cannot be "entirely objective" (Gabriel). All students indicated that there was often more than one way to mathematize problem situations involving social issues. The transformation of many of these issues into mathematics problems involved a number of choices. People make these choices, said the students. So, while logic and the mathematical constructs themselves were perceived as neutral and value-free, their use was not. Some students indicated that one can selectively feature evidence that confirms what one expects to find or one can overstate the conclusion that can be drawn from the inquiry to advance one's agenda. For Bohl (1998), mathematics applications are strongly influenced by the broader social and political contexts in which they are developed and used. Issues of domination, power, and ideology embedded in these contexts must be addressed through a questioning of the factors that shape the application of mathematics knowledge. While students understood that the interests and values of the individuals influence mathematics applications, they did not link these individuals to social groups and ideas about how domination works. Doing so would have made their reflections on subjectivity more fully "critical."

Critical mathematics education scholars assert that a concerning consequence of the mystification of mathematics is that it inhibits the questioning of applications of mathematics. This point was not lost on students. As Madison observed, "They (take) advantage of people who aren't going to look into things better, not taking the time to look, or not going to know to look." The questioning of received knowledge about mathematics and its uses, regardless of the source of this knowledge, is central to a mathematics literacy that is "critical." All students mentioned the importance of closely examining a mathematical inquiry and deciding on the merits of the inquiry whether to accept its claims as true. A lot of people think because it's math, it must be true," stated Lauren when it might well be "meaningless," added Adam. In viewing the judgment of human beings as paramount, students contested a dominant myth of mathematics as an "above-all referee...one that is above humans" (Borba \& Skovsmose, 1997, p. 17). At the same time, students expressed doubt that most people (themselves included) could judge all aspects of social inquiries involving mathematics. Doing so requires knowledge of the subject matter and mathematical tools that most of the population lacks. Thus, reliance on the judgments of experts is unavoidable. This reflection echoes Skovsmose's discussion of one effect of the use of mathematics on social problem solving: it limits the number of people who can participate in a comprehensive critique of a mathematics application. 


\section{Conclusions}

Critical mathematics education scholars argue that students' views of mathematics and society will be less mystified if they experience the use of mathematics as a tool for social critique. This study supports this relationship between classroom experiences and students' perceptions of mathematics and the world in which they live. As the study findings demonstrate, their mathematically-based investigations enabled students to see that social inequality in the USA has not yet been relegated to the dustbin of history despite the social progress of recent decades. They also enabled them to experience the power and the limitations of mathematics as a tool for social critique. Furthermore, their investigations impressed upon them the importance of interrogating the assumptions, methods, and conclusions of a mathematics application as well as the intentions of its developers and users. Students' views of mathematics were "critical" in some important ways.

There is very little information in the research literature about high school students' views of mathematics as a tool for social critique. This study contributes a description of students' views that is grounded in their experiences using mathematics to investigate social issues. It is noteworthy that all students in this study indicated that they had not previously explored social justice issues in a mathematics classroom.

This study also contributes to the literature an examination of their views of mathematics from a critical theoretical perspective on mathematics literacy. In linking mathematical competencies to an enhanced consciousness of the social world and in recognizing the affordances and constraints of mathematics as a tool for social critique, critical mathematics literacy is a mathematics literacy that promotes social justice and thereby, the liberation of the potential of all human beings. The perspective of the critical education tradition has been mostly absent from the public and professional discourses on mathematics education reform. By investigating students' views of mathematics from the standpoint of this tradition, this study informs ongoing conversations about what ought to constitute mathematics literacy.

\section{References}

Apple, M. (1992). Do the standards go far enough? Power, policy, and practice in mathematics education. Journal for Research in Mathematics Education, 23(5), 412-431.

Bohl, J. (1998). Critical mathematics education: An exploration of existing curricular materials. Unpublished master's thesis, University of Wisconsin, Madison Wisconsin, Madison.

Borba, M., \& Skovsmose, O. (1997). The ideology of certainty in mathematics education. For the Learning of Mathematics, 17(3), 17-23.

Brantlinger, A. (2007). Geometries of inequality: Teaching and researching critical mathematics in a low-income urban high school (Doctoral dissertation, 
Northwestern University, 2007). Dissertation Abstracts International, 68-03A, 919.

Burbules, N. (1995). Forms of ideology-critique: A pedagogical perspective. In P. McLaren \& J. Giarelli (Eds.), Critical theory and educational research (pp. 5369). Albany, NY: State University of New York Press.

Christiansen, I. (1996). Mathematical modelling in high school: From idea to practice. Unpublished doctoral dissertation, Aalborg University, Aalborg, Denmark.

Cogan, J. (2000). The challenge of multidimensional citizenship for the $21^{\text {st }}$ century. In J. Cogan \& R. Derricott (Eds.), Citizenship for the 21 $1^{\text {st }}$ century: An international perspective on education (pp. 171-183). London: Kogan Page.

D'Ambrosio, U. (2008). Peace, Social Justice and Ethnomathematics. In B. Sriraman (Ed.), International Perspectives on Social Justice in Mathematics Education (pp. 37-50). Charlotte, NC: Information Age Publishing.

Davis, P. (1993). Applied mathematics as social contract. In S. Restivo, J. Van Bendegem, \& R. Fischer (Eds.), Math worlds: Philosophical and social studies of mathematics and mathematics education (pp. 182-194). Albany, NY: State University of New York.

Erickson, F. (1986). Qualitative methods in research on teaching. In M. C. Wittrock (Ed.), Handbook of research on teaching (3rd ed.) (pp. 119-161). New York: MacMillan.

Ernest, P. (1991). The philosophy of mathematics education. New York: Falmer Press.

Forman, S., \& Steen, L. (2000). Beyond eighth grade: Functional mathematics for life and work. In M. Burke \& F. Curcio (Eds.), Learning mathematics for a new century. Reston, VA: National Council of Teachers of Mathematics.

Frankenstein, M. (1989). Relearning mathematics: A different third $R$-radical maths. London: Free Association Books.

Frankenstein, M. (1990). Incorporating race, gender, and class into a critical mathematical literacy curriculum. Journal of Negro Education, 59(3), 336-347.

Frankenstein, M. (1994). Understanding the politics of mathematical knowledge as an integral part of becoming critically numerate. Radical Statistics, 56, 22-40.

Frankenstein, M. (1995). Equity in mathematics education: Class in the world outside the class. In W. G. Secada, E. Fennema, \& L. Adajian (Eds.), New directions for equity in mathematics education (pp. 165-190). New York: Cambridge University Press.

Freire, P. (1995). Pedagogy of the oppressed (Translated by M.B. Ramos.). New York: Continuum.

Gellert, U., Jablonka, E., \& Keitel, C. (2001). Mathematical literacy and common sense in mathematics education. In B. Atweh, H. Forgasz, \& B. Nebres (Eds.), Sociocultural research on mathematics education: An international perspective (pp. 57-73). Mahwah, NJ: Erlbaum.

Gutstein, E. (2003). Teaching and learning mathematics for social justice in an urban Latino school. Journal for Research in Mathematics Education, 34(1), 37-73.

Gutstein, E. (2006). Reading and writing the world with mathematics: Toward a pedagogy for social justice. New York: Taylor \& Francis Group.

National Council of Teachers of Mathematics. (2000). Principles and standards for school mathematics. Reston, VA: Author.

National Governors Association Center for Best Practices \& Council of Chief State School Officers. (2010). Common Core State Standards for Mathematics. Washington, DC: Authors. 
Noddings, N. (1993). Politicizing the mathematics classroom. In S. Restivo, J. Van Bendegem, \& R. Fischer (Eds.), Math worlds: philosophical and social studies of mathematics and mathematics education (pp. 150-161). Albany, NY: State University of New York.

Porter, T. (1995). Trust in numbers: The pursuit of objectivity in science and public life. Princeton, NJ: Princeton University Press.

Skovsmose, O. (1994a). Towards a critical mathematics education. Educational Studies in Mathematics, 27, 35-57.

Skovsmose, O. (1994b). Towards a philosophy of critical mathematics education. Dordrecht, The Netherlands: Kluwer Academic.

Spradley, J. (1980). Participant observation. New York: Holt, Rinehart, \& Winston.

Steen, L. (Ed.). (1997). Why numbers count: Quantitative literacy for tomorrow's America. New York: College Entrance Examination Board.

Tate,W. (1995). Returning to the root: A culturally relevant approach to mathematics pedagogy. Theory into Practice, 34(3), 166-173.

Tate, W. (1996). Mathematizing and the democracy. In C. Grant \& M. Gomez (Eds.), Making schooling multicultural: Campus and classroom (pp. 186-201). Englewood Cliffs, NJ: Merrill.

Turner, E. (2003). Critical mathematical agency: Urban middle school students engage in mathematics to investigate, critique, and act upon their world (Doctoral dissertation, University of Texas at Austin, 2003). Dissertation Abstracts International, 65-01A, 98.

Wilkins, J. (2000). Preparing for the 21 st century: The status of quantitative literacy in the United States. School Science and Mathematics, 100(8), 405-418 
